\title{
A IMPLANTAÇÃO DE PROGRAMAS E AÇÕES INCLUSIVAS EM UM MUNICÍPIO DO OESTE PAULISTA: PDDE ACESSIBILIDADE
}

Ana Mayra Samuel da Silva, Elisa Tomoe Moriya Schlünzen, Danielle Aparecida do Nascimento dos Santos, Ana Virginia Isiano Lima

Universidade Estadual Paulista - UNESP, Programa de Pós-Graduação em Educação, Presidente Prudente, SP. Universidade do Oeste Paulista - UNOESTE, Programa de Pós-Graduação Lato Sensu, Presidente Prudente, SP. E-mail: elisa@eduapps.unesp.br, danielle@unoeste.br, ana.mayra.ss@gmail.com, anaisianolima@gmail.com

Agência Financiadora: Coordenação de Aperfeiçoamento de Pessoal de Nível Superior (CAPES)

\section{RESUMO}

Para que todos sejam incluídos de acordo com as suas necessidades e especificidades, os objetivos propostos pela educação escolar precisam estar direcionados ao reconhecimento e à problematização das diferenças. O objetivo deste estudo foi analisar a implantação de programas e ações propostos no âmbito da Política Nacional de Educação Especial na perspectiva da Educação Inclusiva (BRASIL, 2008), em uma escola localizada em um município de pequeno porte do oeste paulista. A metodologia constou de intervenção formativa sobre políticas públicas educacionais, programas e ações em uma perspectiva inclusiva, e, observação participante para acompanhamento das ações desenvolvidas pela equipe gestora escolar, a partir de uma abordagem qualitativa. Os programas e ações do Ministério de Educação são efetivos, pois, visam contribuir e auxiliar com a garantia, não apenas do acesso, mas também da permanência com qualidade dos estudantes no contexto escolar.

Palavras-chave: Inclusão Escolar. Programas e Ações. PDDE Acessibilidade.

\section{IMPLANTATION OF INCLUSIVE PROGRAMS AND ACTIONS IN A MUNICIPALITY OF WEST PAULISTA: PDDE ACCESSIBILITY}

\begin{abstract}
In order for all to be included according to their needs and specificities, the objectives proposed by school education must be directed to the recognition and problematization of differences. The objective of this study was to analyze the implementation of programs and actions proposed in the scope of the National Policy of Special Education from the perspective of Inclusive Education (BRASIL, 2008), in a school located in a small municipality in the west of São Paulo. The methodology consisted of formative intervention on public educational policies, programs and actions in an inclusive perspective, and participant observation to follow the actions developed by the school management team, based on a qualitative approach. The programs and actions of the Ministry of Education are effective, since they aim to contribute and help with the guarantee, not only of access, but also of the permanence with the quality of students in the school context.
\end{abstract}

Keywords: School Inclusion. Programs and Actions. PDDE Accessibility. 


\section{INTRODUÇÃO}

A democratização do acesso ao ensino, no Brasil, resultou em uma escola aberta para todos, que, ainda hoje, enfrenta desafios para reconhecer e problematizar as diferenças das pessoas que frequentam este ambiente e garantir permanência e educação com qualidade. Considerando a inclusão de EPAEE no contexto da escola regular, podemos afirmar que, passaram por um processo histórico e legal que resultou em diversos benefícios, dos quais se pode desfrutar hoje.

No entanto, a Educação Especial, constituiu-se como um espaço de formação sem interlocução com a educação comum, o que acabou resultando em pensamentos ambíguos, embora trouxesse inúmeros benefícios para o processo de escolarização dos EPAEE na escola comum. Dada a sua transversalidade e o que consta na atual política educacional, a Educação Especial representa avanços significativos para a Educação Inclusiva, uma vez que garantiu serviços a serem prestados a estes estudantes em escolas regulares.

Nesse contexto, a Constituição Federal de 1988 se instaurou no Brasil como um estatuto para a população brasileira. No que diz respeito ao acesso à escolarização, este documento legal, garantiu a universalização do direito à Educação, assegurando acesso e permanência com qualidade.

Dessa forma, o Governo Federal passou a fomentar ações, visando a efetivação da Constituição em vigor. Kassar (2011) contextualiza, afirmando que após a promulgação da Constituição Federal, o Brasil passou a investir em leis e decretos que garantissem o cumprimento do documento legal.

O Brasil participou em 1990 da Conferência Mundial sobre Educação para Todos, em Jomtien na Tailândia, tornando-se signatário da Declaração Mundial sobre Educação para Todos. Em seguida, ocorreu a elaboração do Plano Decenal de Educação para todos (BRASIL, 1993), que teve por objetivo assegurar a todos os brasileiros "conteúdos mínimos de aprendizagem que atendam necessidades elementares da vida" (BRASIL, 1993, p. 13).

Diversas outras iniciativas e ações foram fomentadas ao longo dos anos, visando garantir o acesso e permanência com qualidade, para todos os cidadãos brasileiros. Vale lembrar, que este movimento de inclusão não aconteceu apenas no Brasil, mas também em diversos outros países.

O Governo Federal, ao desenvolver políticas públicas educacionais que visam a inclusão escolar, como por exemplo Diretrizes Nacionais para a Educação Especial na Educação Básica, da Resolução Conselho Nacional de Educação/Câmara de Educação Básica no 2/2001 (BRASIL, 2001), passou a garantir a matrícula de todos os estudantes em salas comuns de escolas regulares, acompanhado, ou não, de maneira complementar ou suplementar, de um AEE.

Ao reconhecer as dificuldades enfrentadas pelos sistemas de ensino brasileiro para promover o que preconiza os documentos legais, evidenciou-se a necessidade de confrontar as práticas discriminatórias ainda existentes e criar alternativas para superá-las. Assim, a Política Nacional de Educação Especial na Perspectiva da Educação Inclusiva (BRASIL, 2008), inaugurou-se no cenário brasileiro como um documento legal importante, que teve por intuito nortear a prática de gestores educacionais e escolares para promover a inclusão de EPAEE.

A Política Nacional de Educação Especial na Perspectiva da Educação Inclusiva, documento elaborado pela Secretaria de Educação Continuada, Alfabetização, Diversidade e Inclusão (SECADI), e do Ministério de Educação (MEC), em 2008, inaugurou no cenário brasileiro um paradigma educacional fundamentado na construção de sistemas educacionais formais inclusivos, por meio da organização da escola comum em conjunto com a Educação Especial. Esse novo paradigma congrega importantes mudanças estruturais da escola comum, que deve pensar nas especificidades de todos os estudantes em termos não só de acesso à escolarização, mas também de oportunidades de aprendizado e de desenvolvimento de seus potenciais. Conforme esse documento, 
[...] a educação inclusiva constitui um paradigma educacional fundamentado na concepção de direitos humanos, que conjuga igualdade e diferença como valores indissociáveis, e que avança em relação à ideia de equidade formal ao contextualizar as circunstâncias históricas da produção da exclusão dentro e fora da escola (BRASIL, 2008, p. 1).

Para além dessas afirmações o documento supracitado sugere algumas orientações para os sistemas educacionais, como a criação de redes de apoio, interlocução com profissionais da educação especial, intersetorialidade e interdisciplinaridade. Após este documento legal o MEC, juntamente com a SECADI, investiu, com mais vigor, em Programas e Ações que podem ser desenvolvidas pelos gestores educacionais e escolares para promover uma educação com qualidade para todos. Com isso, procurou evidenciar em seu corpo alguns objetivos e alternativas para a (re)organização das escolas e sua mudança estrutural e cultural a fim de atender a diversidade das diferenças.

Com a homologação da Política Nacional de Educação Especial na Perspectiva da Educação Inclusiva (BRASIL, 2008) cerca de $50 \%$ das pessoas com deficiências brasileiras estavam matriculadas nas escolas. O Documento Subsidiário da SECADI, publicado em 2015, afirma que em 2014 haviam registradas 633042 (seiscentos e trinta e três mil e quarenta e duas) matrículas de estudantes com deficiência no Brasil. Para ilustrar, segue abaixo o infográfico publicado no Documento Subsidiário (BRASIL, 2015).

Figura 1. Infográfico do Documento Subsidiário da SECADI.

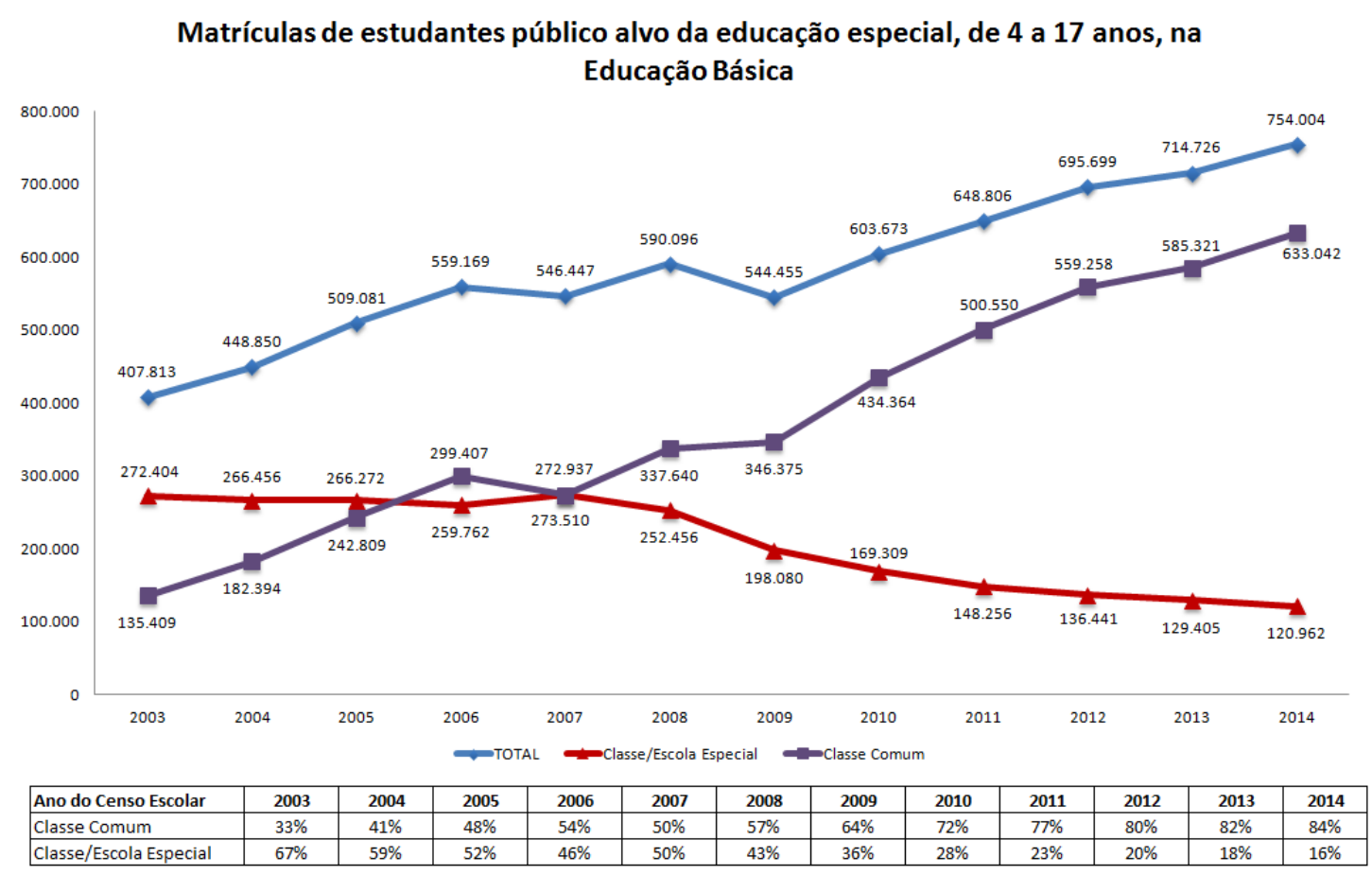

Fonte: (BRASIL, 2015).

Conforme pode ser observado, de 2003 a 2014, em 11 anos, o número de matrícula na classe comum aumentou em $407,34 \%$. Na escola especial teve uma queda de $44,41 \%$ e no total o aumento foi de $184,83 \%$. Além disso, nos dados do MEC divulgados pela SECADI em 2015, 7\% (sete por cento) dos estudantes brasileiros com deficiência estavam na Educação Infantil,73\% (setenta e três por cento) no ensino fundamental, 6\% (sete por cento) no ensino médio, 13\% (treze por cento) na educação de jovens e adultos, e 1\% na educação profissional e tecnológica, até 2014. 
Atualmente, não se pode compreender a permanência com qualidade como condições para o acesso à escola, é necessário aprofundar essa discussão e ter o entendimento de que pertencer, fazer parte, ser reconhecido e atuar como sujeito ativo do próprio processo de ensino e aprendizagem no âmbito escolar é fundamental para que a inclusão aconteça, conforme preconizam os documentos legais.

De acordo com Cury (2002), a educação precisa ser vista como um canal de acesso aos bens sociais e à luta política, bem como, um caminho para a emancipação do indivíduo diante de sua insipiência. Assim, lutar pela democratização do ensino deve extrapolar as dimensões políticas, pois, precisa estar diretamente relacionada ao indivíduo e às diferenças que o caracterizam.

Bergamo (2009) apresenta a inclusão como "um movimento que compreende a educação como direito humano fundamental e a base para uma sociedade mais justa, que se preocupa em atender todas as pessoas". A autora afirma que as escolas, e sociedade em modo geral, devem estar abertas a todos, independentemente de suas diferenças que os caracterizam.

Segundo Lima (2017) o direito de acesso e permanência na escola a todos os estudantes se configurou como uma conquista, principalmente para aqueles que antes permaneciam excluídos do contexto escolar. A partir da democratização do ensino, com bases nos documentos legais expostos acima, diversas iniciativas governamentais surgiram com o intuito de mudar o cenário educacional.

O espaço escolar, enquanto ambiente transformador para uma sociedade mais inclusiva, oportuniza aos estudantes a convivência com as diferenças que caracterizam as pessoas. Assim, pode-se afirmar que, com a reorganização da escola, a conscientização, formação e mudanças de práticas da equipe gestora, professores e funcionários, será possível proporcionar a todos o privilégio de conviver em um ambiente educativo heterogêneo, onde todos são respeitados.

Nesse sentido, objetivo desde artigo é: analisar a implantação de programas e ações propostos no âmbito da Política Nacional de Educação Especial na perspectiva da Educação Inclusiva (BRASIL, 2008), em uma escola localizada em um município de pequeno porte do oeste paulista.

\section{METODOLOGIA}

A abordagem metodológica do estudo desenvolvido é qualitativa, pois permite refletir sobre as singularidades do cotidiano escolar. Segundo Richardson (2012, p. 80),

[...] os estudos que empregam uma metodologia qualitativa podem descrever a complexidade de determinado problema, analisar a interação de certas variáveis, compreender e classificar processos dinâmicos vividos por grupos sociais, contribuir no processo de mudança de determinado grupo e possibilitar, em maior nível de profundidade, o entendimento das particularidades do comportamento dos indivíduos.

Com essa premissa, o objetivo proposto está relacionado ao conhecimento, compreensão e análise do contexto a ser estudado. A abordagem qualitativa permite entender a natureza de um fenômeno social e buscar compreensões teóricas e práticas para situação vivenciada. A pesquisa tem autorização ética mediante cadastro no Comitê de Ética e Pesquisa, (CAAE): 55532916.0.0000.5402, tendo em vista que emerge do estudo realizado para elaboração da Dissertação intitulada "Gestão Escolar: a consolidação de uma escola inclusiva mediante a intersetorialidade".

O estudo foi desenvolvido no âmbito da Escola Municipal de Ensino Fundamental (EMEF) "S", com aproximadamente 380 estudantes, localizada em um município de pequeno porte do interior do oeste paulista. A partir do conhecimento da realidade e do contexto da unidade escolar optou-se por buscar intervir para possibilitar a construção de uma cultura inclusiva, mediante o 
interesse da equipe de gestão escolar, que compreender a diretora escolar (DR), a vice-diretora (VD) e a coordenadora pedagógica (CP), participantes do estudo, pela temática.

Dessa forma, sentiu-se a necessidade de estudar sistematicamente com a equipe gestora escolar as políticas públicas que tange a Educação Especial na Perspectiva da Educação Inclusiva, a fim de compreender e transformar o conceito de inclusão adotado pela unidade escolar. Percebeu-se que a equipe de gestão escolar, por possuir um cotidiano permeado por decisões administrativas, burocráticas e pedagógicas, além das intervenções entre estudantes, professores e funcionários, não encontrava tempo para se dedicar aos estudos sobre a inclusão escolar e realizar ações que possibilitasse a construção de uma cultura inclusiva.

Procurou-se intervir com a equipe gestora escolar a partir de leituras e discussões sobre as políticas públicas educacionais e, principalmente, programas e ações do Ministério de Educação referentes à inclusão escolar, a fim de que os participantes da pesquisa passassem a refletir sobre a educação inclusiva em sua unidade escolar e (re)pensassem suas ações enquanto gestores da escola, com o intuito de garantir aos estudantes um ambiente educacional inclusivo.

Além disso, foi realizada a observação participante pois permitiu coletar informações para examinar posteriormente os fenômenos que aconteceram após as leituras e discussões sobre as políticas, programas e ações em uma perspectiva inclusiva. De acordo com Marconi e Lakatos (2010, p. 176), na observação participante "o observador sabe o que procura e o que carece de importância em determinada situação; deve ser objetivo, reconhecer possíveis erros e eliminar sua influência sobre o que vê ou recolhe". A observação permitiu compreender as especificidades da realidade escolar bem como as ações da equipe gestora escolar para proporcionar igualdade em condições de acesso e permanência com qualidade.

\section{RESULTADOS}

\section{O PDDE Acessibilidade e a Constituição de uma Escola Inclusiva}

As ações desenvolvidas pelo MEC para melhorar a qualidade da educação em escolas públicas são diversas. Os programas e ações perpassam a valorização e a formação dos profissionais da educação, a infraestrutura arquitetônica e pedagógica da escola, a aprendizagem dos estudantes, e o apoio aos pais ou responsáveis. Todos esses programas e ações buscam incidir sobre os fatores que promovem o que preconiza os documentos legais: igualdade em condições de acesso e permanência com qualidade de todos os estudantes, com redução de desigualdades, equidade, reconhecimento e respeito às diferenças.

Os recursos do programa PDDE Acessibilidade são transferidos para as unidades escolares, com base no número de estudantes matriculados, de acordo com dados extraídos do censo escolar realizado pelo Instituto Nacional de Estudos e Pesquisas Educacionais Anísio Teixeira (INEP), no ano anterior ao repasse do recurso. De acordo com o exposto, a EMEF "S." foi contemplada por este programa pois possui seis EPAEE, com laudo, cadastrados no Sistema de Gestão Dinâmica de Administração Escolar (GDAE), e aproximadamente quinze estudantes passando por diagnóstico. Ou seja, possuem uma quantidade significativa de estudantes que justifica a contemplação pelo projeto.

Vale destacar que a aquisição e compra dos recursos aconteceu após o período de intervenção formativa do trabalho de campo da investigação, visto que a escola foi contemplada pelo programa em 2016 e só descobriu o ocorrido em Maio de 2017, pois estavam acompanhando a solicitação da SRM do MEC. Os recursos adquiridos auxiliam o desenvolvimento dos atendimentos educacionais especializados que iniciaram no segundo semestre letivo de 2017, bem como com a acessibilidade da unidade escolar.

A EMEF "S." recebeu um total de dez mil reais para serem gastos com acessibilidade ao ambiente físico, aos recursos didáticos e pedagógicos e a comunicação e informação. A gestão escolar optou por destinar a verba para aquisição de recursos didático-pedagógicos para a SRM 
itinerante que foi implementada em agosto de 2017, bem como aquisição de materiais destinados à adaptação de banheiros, corrimãos e fitas antiderrapantes para escadas e degraus, conforme a Figura 2.

Figura 2. Recursos adquiridos pelo PDDE Acessibilidade.

Fonte: autora (2018)

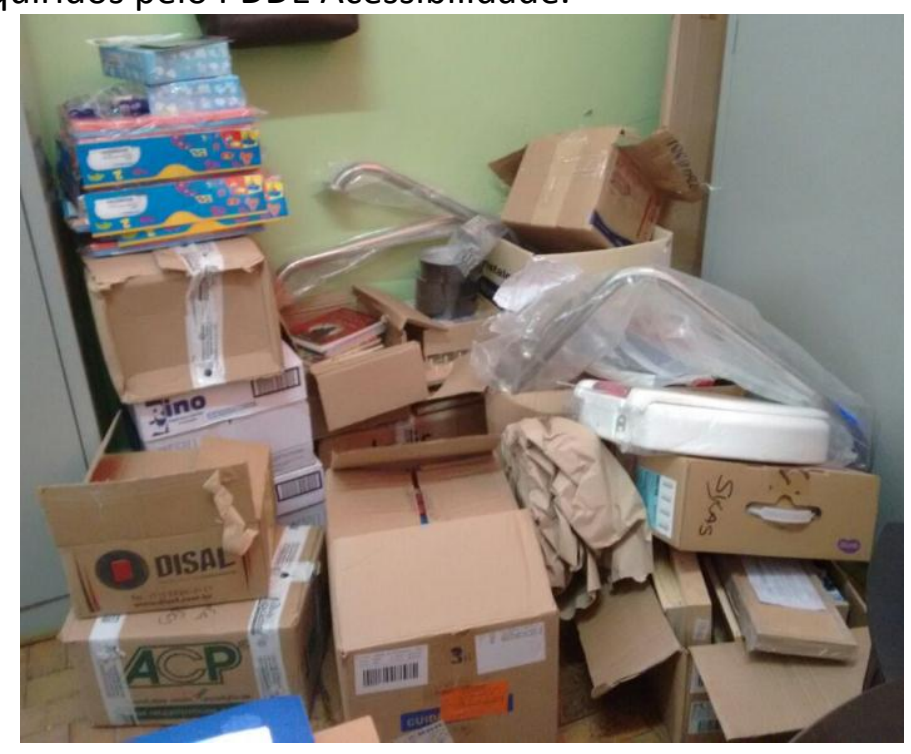

Para instalação dos recursos adquiridos destinados à acessibilidade física da unidade escolar, a equipe de gestão solicitou apoio da Divisão Municipal de Educação, que atendeu solicitamente e disponibilizou mão de obra para instalação dos mesmos. A Figura 3 e a Figura 4 revelam a instalação dos materiais destinados às adaptações físicas. Além disso, por perceber que a unidade escolar estava passando por transformações físicas, ideológicas e pedagógicas, a Divisão Municipal de Educação passou a acompanhar esse processo, apoiando sempre que necessário e possível.

Figura 3. Recursos adquiridos pelo PDDE Acessibilidade.

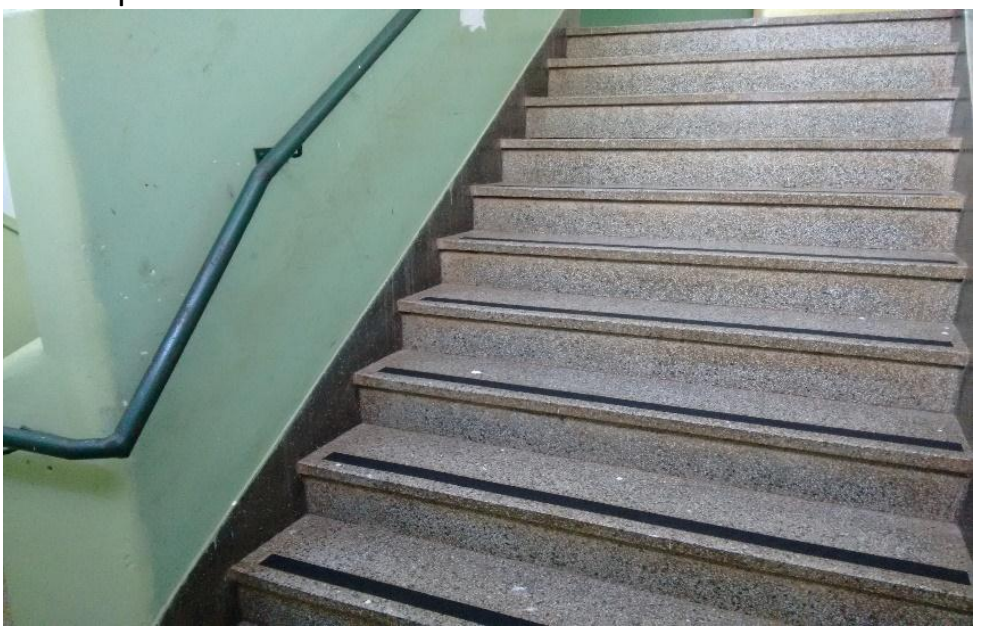

Fonte: autora (2018)

É importante afirmar que os corrimões e fitas antiderrapantes nas escadas e o banheiro acessível na unidade escolar ainda eram um projeto a longo prazo, tendo em vista que, por ordens judiciais, a Divisão Municipal de Educação juntamente com o departamento de obras municipais havia realizado no ano corrente de 2016 um checklist de adaptações arquitetônicas que deveriam ser realizadas nas unidades escolares. Com o PDDE Acessibilidade foi possível adquirir os recursos 
necessários para instalação do corrimão, das fitas antiderrapantes e do banheiro acessível e sua sinalização aos professores, funcionários e estudantes que deles necessitam.

Figura 4. Recursos adquiridos pelo PDDE Acessibilidade.

Fonte: autora (2018)

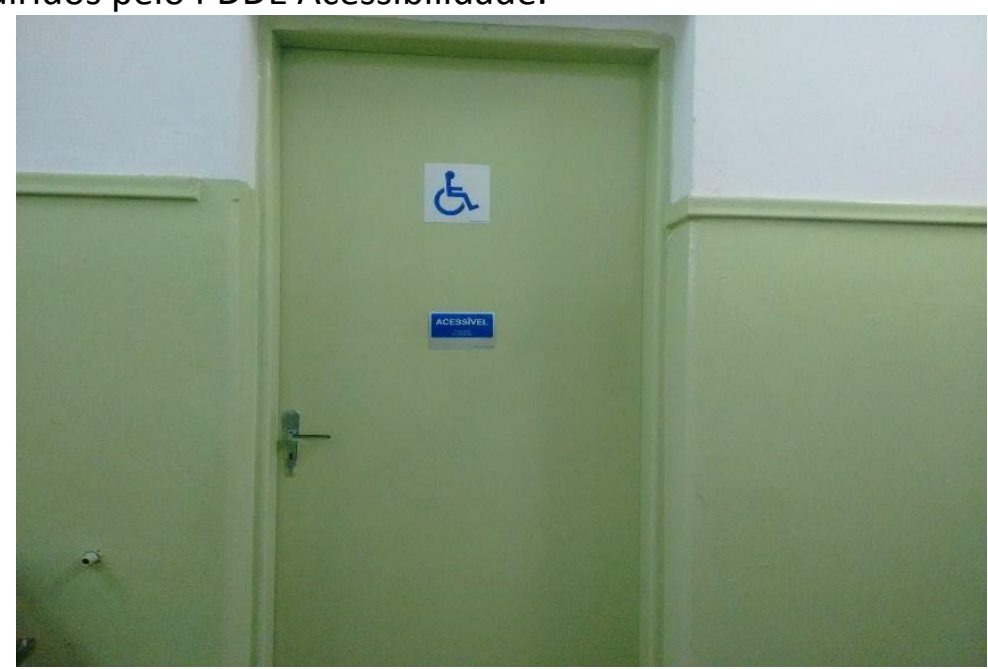

O fato da escola ter sido contemplada com o PDDE Acessibilidade foi um fator fundamental para incentivar as representantes da Divisão Municipal de Educação a apoiar e colaborar com o projeto piloto da Sala de Recursos Multifuncionais na EMEF "S". Pois a equipe gestora apresentou como argumento necessitar apenas dos profissionais para atuar na SRM, tendo em vista que os recursos didático-pedagógicos já haviam sido adquiridos pelo PDDE Acessibilidade e também por meio de doações.

Inicialmente, antes de saber que havia sido contemplada pelo PDDE Acessibilidade a gestão havia se comprometido em oferecer recursos didático-pedagógicos e de tecnologia assistiva, pois no ano de 2015 foi contemplada por um programa social do Banco do Brasil com recursos específicos para o ensino de estudantes com Deficiência Visual. Dessa forma, a escola já possuía lupas, acionadores, colmeia, globo terrestre tátil, impressora e máquina braile, entre outros. $\mathrm{Na}$ Figura 5 pode-se perceber a presença desses recursos no armário da SRM, visto que atende estudantes com baixa visão. 
Figura 5. Recursos adquiridos pelo PDDE Acessibilidade e doados por um programa social do Banco do Brasil.

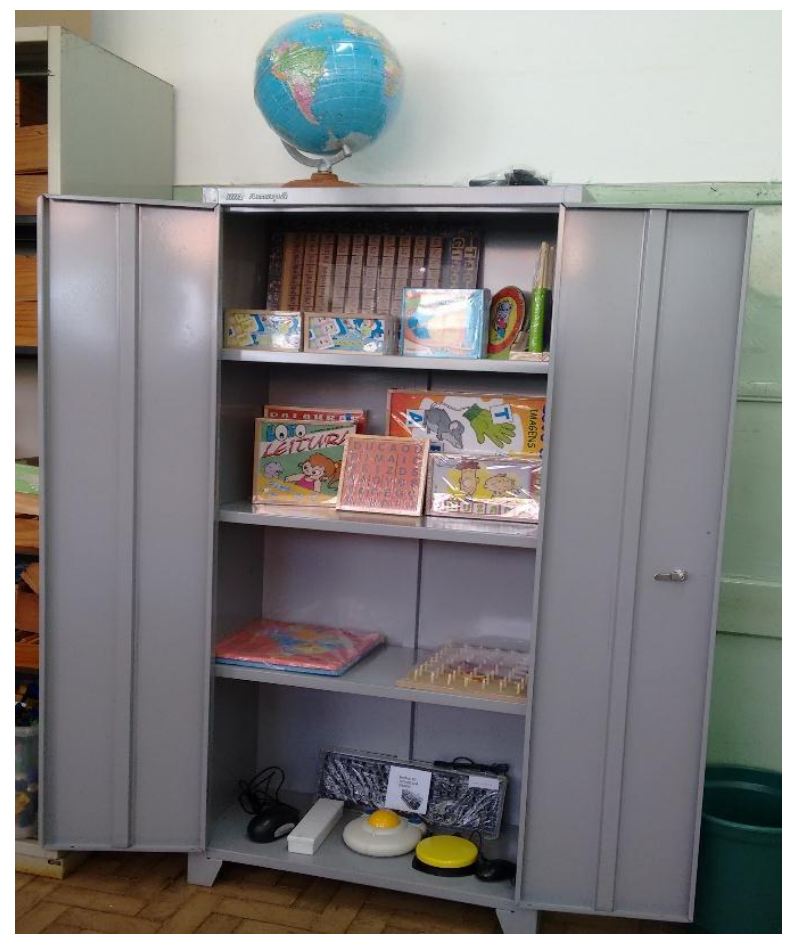

Fonte: autora (2018)

Diante do exposto, percebe-se que o PDDE Acessibilidade, no contexto da EMEF "S" foi efetivo para proporcionar igualdade em condições de acesso e melhorar a qualidade do ensino ofertado. Uma vez que as ações desenvolvidas pela equipe de gestão escolar, com a verba do programa, já constavam como metas a curto, médio e longo prazo no PME, e, também estavam no plano de ação da gestão educacional municipal, uma vez que, conforme já mencionado, estavam passando por fiscalização judicial.

É válido destacar que para se tornar efetivo, um programa ou ação do MEC precisa ser constantemente fiscalizado e acompanhado por órgãos superiores, uma vez que ao invés de adquirirem recursos para acessibilidade arquitetônica e pedagógica, a equipe gestada da EMEF " $\mathrm{S}$ " poderia ter adquirido recursos relacionados às demais demandas escolares.

Nesse sentido, os programas e ações do MEC são efetivos pois visam contribuir e auxiliar com a garantia, não apenas do acesso, mas também da permanência com qualidade dos estudantes no contexto escolar. Para tanto, gestão educacional e escolar, precisam agir como fiscais que cobrem tanto do governo como dos profissionais da educação responsáveis pela execução dos programas e ações.

\section{DISCUSSÃO}

\section{Programas e Ações da Política Nacional de Educação Especial na Perspectiva da Educação Inclusiva}

O AEE é um serviço de apoio complementar e/ou suplementar à classe comum, iniciativa considerada pelo MEC como um grande avanço para a década em termos de educação. O AEE é destinado aos EPAEE e é realizado nas Salas de Recursos Multifuncionais (SRM), no caso de escolas municipais, ou Salas de Recursos (SR), no caso de escolas estaduais. Por meio do AEE surge no ambiente escolar a perspectiva de transpor as barreiras junto às dificuldades dos estudantes, e a necessidade de implementar condições adequadas de acessibilidade para a melhora na sua comunicação e mobilidade, bem como contribuir para sua independência e autonomia. Este atendimento pode ser considerado como, 
uma ação do sistema de ensino no sentido de acolher a diversidade ao longo do processo educativo, constituindo-se num serviço disponibilizado pela escola para oferecer o suporte necessário às necessidades educacionais especiais dos alunos, favorecendo seu acesso ao conhecimento (BRASIL, 2006a, p. 15).

Para validação desse programa do MEC, o Decreto 7611/2011 dispõe sobre o AEE e modifica algumas regras do Fundo de Manutenção e Desenvolvimento da Educação Básica e de Valorização dos Profissionais da Educação (FUNDEB), que passa a garantir recursos extras aos estudantes que efetivamente estejam matriculados em escolas públicas e participando do AEE. (BRASIL, 2011)

Para o desenvolvimento do AEE nas escolas, o MEC investiu no Programa de Implantação de SRM, que distribuiu recursos para montagem de SRM para escolas comuns da rede pública de ensino, sem nenhum custo. As SRM são ambientes dotados de equipamentos, mobiliários e materiais didáticos e pedagógicos para a oferta do AEE. As SRM funcionam de forma não substitutiva à escolarização, pois visam a consolidação de um sistema educacional inclusivo que possibilite garantir uma educação de qualidade a todos, em todos os níveis, etapas e modalidades, disponibilizando recursos e serviços.

Além disso, outros programas e ações foram se materializando para a constituição da educação inclusiva. O Programa Nacional de Formação Continuada de Professores na Educação Especial, teve por objetivo apoiar a formação continuada de professores para atuar nas SRM e em salas de aula comuns do ensino regular, em parceria com as Universidades. Por meio deste programa são oferecidos cursos de nível de aperfeiçoamento e especialização, na modalidade à distância, semipresencial ou presencial. Para solicitar este programa os gestores das escolas precisam apresentar por meio do Plano de Desenvolvimento da Escola (PDE), a demanda de formação.

O Programa de Formação de Professores para o AEE, teve por objetivo oferecer formação continuada de professores que desejam atuar em SRM. Este programa foi realizado, prioritariamente por meio da modalidade a distância. O Programa, na modalidade a distância teve por intuito apoiar os sistemas de ensino na formação continuada de professores. Na modalidade presencial este programa teve por objetivo proporcionar a formação continuada em educação especial. Foram ofertados entre 2007 e 2010: três cursos de especialização e doze cursos de aperfeiçoamento.

O Benefício de Prestação Continuada da Assistência Social (BPC), contribui realizando acompanhamento e monitoramento de acesso e permanência de todas as pessoas em idade escolar, em escolas públicas do ensino regular. No entanto, os estudantes precisam ser beneficiários do BPC, e possuir até 18 anos de idade. De acordo com o Documento Subsidiário da SECADI (BRASIL, 2015), houve crescimento do número de matrículas de estudantes com deficiência que foram beneficiários do BPC.

Em 2007, foram 19 identificadas 78.848 matrículas de beneficiários do BPC com deficiência, representando $21 \%$ do total de beneficiários, na faixa etária de 0 a 18 anos. Em 2012, foram identificadas 329.801 matrículas, correspondendo a 70,16\%. Em termos absolutos, constata-se crescimento de $318,27 \%$, e em termos percentuais, verifica-se o crescimento de 49,16 pontos (BRASIL, 2015, p. 18-19).

Conforme os dados expostos acima, pode-se perceber a importância deste programa para o processo de inclusão escolar em nosso pais.

O Programa Educação Inclusiva: Direito à Diversidade tem por objetivo apoiar a formação de gestores e educadores, a fim de transformar os sistemas educacionais em sistemas educacionais inclusivos. Para tanto, são realizados seminários de formação dos dirigentes e coordenadores escolares, prestação de apoio técnico e financeiro para orientação e organização 
da formação de gestores e educadores, além da disponibilização de referenciais pedagógicos para a formação.

Com esse Programa, o Governo Federal se comprometeu em fomentar a política de constituição de sistemas educacionais inclusivos. As diretrizes principais do programa são: disseminar a política de educação inclusiva nos municípios brasileiros e apoiar a formação de gestores e educadores para efetivar a transformação dos sistemas educacionais e efetivação da inclusão escolar. O princípio que o fundamenta é a "garantia do direito dos alunos com necessidades educacionais especiais de acesso e permanência, com qualidade, nas escolas da rede regular de ensino" (BRASIL, 2006b, p. 9).

O Programa Incluir, tem por intuito fomentar a criação e a consolidação de núcleos de acessibilidade nas Instituições de Ensino Superior, os quais respondem pela organização de ações institucionais que garantam a integração de pessoas com deficiência à vida acadêmica, eliminando barreiras comportamentais, pedagógicas, arquitetônicas e de comunicação.

O Projeto Livro Acessível teve por objetivo promover a acessibilidade no âmbito dos Programas de Livro MEC/FNDE, visando assegurar aos estudantes com deficiência visual matriculados em escolas públicas da educação básica, livros em formatos acessíveis. Para tanto, o MEC desenvolveu um sistema de informação digital acessível, denominado, Mecdaisy; realizou seminários para planejamento das ações que seriam desenvolvidas; disponibilizou computadores para que as escolas fornecessem aos estudantes; criou um acervo digital acessível, entre outros.

O Programa Observatório da Educação teve por intuito promover a formação de mestres e doutores em educação, visando o desenvolvimento de estudos e pesquisas em níveis de pósgraduação.

O Programa Nacional para Certificação de Proficiência no Uso e Ensino da Língua Brasileira de Sinais - LIBRAS e para a Certificação de Proficiência em Tradução e Interpretação da LIBRAS/Língua Portuguesa (PROLIBRAS), tem por objetivo viabilizar, por meio de exames de âmbito nacional, a certificação de proficiência no uso e ensino de LIBRAS e na tradução e interpretação da LIBRAS.

O Programa Escola Acessível tem como objetivo, promover condições de acessibilidade ao ambiente físico, aos recursos didáticos e pedagógicos e a comunicação e informação nas escolas públicas de ensino regular. O programa é viabilizado por meio do Programa Dinheiro Direto na Escola (PDDE) às escolas que já foram contempladas pelo Programa de Implantação de SRM. Este programa financia: adequação arquitetônica como rampas, sanitários, vias de acesso, instalações de corrimão e de sinalização visual tátil e sonora. Além disso, auxilia na aquisição de cadeiras de rodas, recursos de tecnologia assistiva e mobiliários acessíveis.

Conforme exposto anteriormente, desde a Política Nacional de Educação Especial na perspectiva da Educação Inclusiva a SECADI tem investido em programas e ações que proporcionem aos estudantes com deficiência igualdade em condições de acesso e permanência com qualidade. Dessa forma, o PDDE Acessibilidade, exposto como resultado parcial de uma investigação realizada por intermédio do Programa de Pós-Graduação em Educação da Faculdade de Ciências e Tecnologia (FCT/Unesp), destina-se às escolas públicas com uma quantidade expressiva de matrículas no GDAE de estudantes público-alvo da educação especial.

Atualmente, todos esses programas e ações, formam um conjunto de políticas públicas educacionais, que tem por intuito contribuir com a constituição de uma cultura de escola cada vez mais inclusiva, em estabelecimentos de ensino dos diferentes municípios do país. A avaliação e análise sobre a importância destes programas para o cenário educacional brasileiro encontram-se no Documento Subsidiário da SECADI (BRASIL, 2015), bem como os dados quantitativos relacionados aos beneficiários dos mesmos. Vale destacar que a diversidade das diferenças presentes no contexto escolar atual evidencia as grandes benfeitorias ocasionadas por estes programas e ações, após a promulgação de documentos legais fundamentais para concebermos a 
educação inclusiva como a temos hoje, como a Política Nacional de Educação Especial na Perspectiva da Educação Inclusiva (BRASIL, 2008).

A Conferência Nacional de Educação (CONAE) de 2010, estabeleceu diferentes recursos para garantir as condições de acesso, acessibilidade e condições de permanência que se vinculam às ações relacionadas,

à diversidade socioeconômica, étnico-racial, de gênero e cultural e à garantia de desempenho satisfatório dos/das estudantes; no caso dos estudantes com deficiência, acompanhamento por profissionais especializados, como garantia de sua permanência na escola e a criação e/ou adequação de espaços às suas condições específicas, garantida pelo poder público. (CONFERÊNCIA NACIONAL DE EDUCAÇÃO, 2010, p. 52)

Além disso, esse documento considerou que, por meio da gestão democrática é possível consolidar uma política que problematize as diferenças, pois garante o diálogo com os movimentos sociais e outros profissionais que podem auxiliar para que a inclusão se efetive no contexto escolar. Para tanto, a escola precisa se organizar de forma a garantir que cada ação resulte em uma contribuição para o processo de escolarização de todos os estudantes. Afinal,

Escola inclusiva é aquela que garante a qualidade de ensino educacional a cada um de seus alunos, reconhecendo a cada um de acordo com suas potencialidades e necessidades. Assim, uma escola somente poderá ser considerada inclusiva quando estiver organizada para favorecer a cada aluno, independentemente de etnia, sexo, idade, deficiência, condição social ou qualquer outra situação. Um ensino significativo é aquele que garante o acesso ao conjunto sistematizado de conhecimentos como recursos a serem mobilizados. (BRASIL, 2004, p. 9)

Diante do exposto, cabe à equipe de gestão educacional ou escolar acessar aos programas e ações do MEC a fim de estabelecer vínculos que possam auxiliar com a constituição de uma cultura de escola mais inclusiva, assegurando recursos, formação, entre outros para atender o que preconiza a política nacional. No entanto, poucos gestores conhecem a proposta do MEC e usufruem de seus programas e ações em seus municípios e instituições escolares. Porém, pode-se afirmar que o MEC e a SECADI investem na divulgação de seus programas e ações, e dos resultados obtidos, que podem comprovar sua eficácia no sistema educacional brasileiro, uma prova disso é o Documento Subsidiário da SECADI publicado em 2015.

\section{CONCLUSÃO}

Para constituir uma escola inclusiva, a equipe de gestão escolar precisa ter consciência de que atua em um cargo político em que é necessário compreender, analisar de maneira crítica a realidade, interpretar e buscar alternativas para administrar, orientar, coordenar e estimular a busca por soluções para os problemas que surgem cotidianamente. Para tanto, a gestão escolar precisa constantemente atualizar seus conhecimentos sobre todas as áreas que tangem a escola, além de se fazer conhecedora dos direitos e deveres de seus professores, funcionários e estudantes.

Diante do estudo realizado, a busca por práticas pedagógicas inclusivas, programas e ações do MEC/SECADI é inerente às atribuições da equipe gestora escolar. Essa busca está expressa na Política Nacional de Educação Especial na Perspectiva da Educação Inclusiva (BRASIL, 2008), e, embora já tenha se passado 10 anos desde a homologação da política, muitos municípios ainda possuem diversas dificuldades para promover ações que favoreçam a inclusão escolar de EPAEE, e por vezes até desconhecem os programas e ações. Nesse sentido, vale colaborar com as equipes escolares a fim de garantir o exposto pela Constituição Federal (BRASIL, 1988): igualdade em condições de acesso e permanência com qualidade para todos. 


\section{REFERÊNCIAS}

BERGAMO, R. B. Pesquisa e Prática Profissional: educação especial. Curitiba: Ibpex, 2009.

BRASIL. Constituição (1988). Constituição da República Federativa do Brasil. Brasília, DF: Senado Federal, 1988.

BRASIL. Decreto 7.611, de 17 de novembro de 2011. Dispõe sobre o atendimento educacional especializado, regulamenta o parágrafo único do art. 60 da Lei no 9.394, de 20 de dezembro de 1996, e acrescenta dispositivo ao Decreto n. 6.253, de 13 de novembro de 2007. Brasília, 2011.

BRASIL. Ministério da Educação. Plano Decenal de Educação para Todos. Brasília: MEC, 1993.

BRASIL. Ministério da Educação. Secretaria de Educação Especial. Diretrizes Nacionais para a Educação Especial na Educação Básica. Brasília: MEC/SEESP, 2001.

BRASIL. Ministério da Educação. Secretaria de Educação Especial. Política Nacional de Educação Especial na perspectiva da Educação Inclusiva. Brasília: MEC/SEESP, 2008.

BRASIL. Ministério da Educação. Secretaria de Educação Especial. Sala de recursos multifuncionais: espaço para atendimento educacional especializado. Brasília: MEC/SEESP 2006.

BRASIL. Ministério Público Federal. Fundação Procurador Pedro Jorge de Melo e Silva (organizadores). O Acesso de Alunos com Deficiência às Escolas e Classes Comuns da Rede Regular. 2. ed. Brasília: Procuradoria Federal dos Direitos do Cidadão, 2004.

BRASIL. Ministério da Educação. Secretaria de Educação Continuada, Alfabetização, Diversidade e Inclusão. Orientações para Implementação da Política de Educação Especial na Perspectiva da Educação Inclusiva.: Documento Subsidiário. Brasília:MEC, 2015.

CONFERÊNCIA NACIONAL DE EDUCAÇÃO (CONAE), 1, 2010, Brasília, DF. Construindo o Sistema Nacional articulado de Educação: o Plano Nacional de Educação, diretrizes e estratégias:

Documento Final. Brasília: MEC, 2010. 164p. Disponível em:

<http://conae.mec.gov.br/images/stories/pdf/pdf/documetos/documento_final.pdf. Acesso em: 05 abr. 2017.

CURY, C. R. J. Direito à Educação: direito à igualdade, direito à diferença. Cadernos de Pesquisa, n. 116, p. 245-262, Jul 2002. Disponível em:

<http://www.scielo.br/scielo.php?script=sci_arttext\&pid=S0100-

15742002000200010\&lng=pt\&tlng=pt>. Acesso em: 10 mar. 2017.

KASSAR, M. C. M. Educação Especial na Perspectiva da Educação Inclusiva: desafios da implantação de uma política nacional. Educar em Revista, Curitiba/PR, n. 41, p. 61-79, jul./set., 2011 DOI: 10.1590/S0104-40602011000300005. Disponível em:

<http://www.scielo.br/scielo.php?script=sci_arttext\&pid=S0104-

40602011000300005\&Ing=pt\&tlng=pt.> Acesso em:

LIMA, A. V. I. Trabalho com Projetos na Perspectiva da Educação Inclusiva com Estudantes em uma Comunidade de Risco. 2017. 124f. Dissertação (Mestrado em Educação) - Universidade Estadual Paulista (UNESP), Faculdade de Ciências e Tecnologia - Presidente Prudente/SP. 
MARCONI, M. A; LAKATOS, E. M. Metodologia do Trabalho Científico. São Paulo: Atlas, 1992.

RICHARDSON, R. J. et al. Pesquisa social: métodos e técnicas. 3. ed. 14. reimpr. São Paulo: Atlas, 2012. 